\title{
Generational Bargain, Transfer of Disadvantages and Extreme Poverty: A Qualitative Enquiry from Bangladesh
}

\section{Owasim Akram ${ }^{1}$ (D) Mathilde Maitrot ${ }^{2}$ (D) Thomas Denk $^{3}$ (D)}

Published online: 26 February 2020

(c) The Author(s) 2020

\begin{abstract}
Why do the poor stay poor? And, crucially, why are their children likely to be poor and end up poor later in life? This is a familiar question in the fields of development, social policy and economics alike. Bangladesh has seen notable successes in reducing poverty, and yet, addressing the transfer of deprivations and disadvantages within and between generations still poses a major challenge for policy-makers. To date, literature on inter-generational poverty remains dominated by large quantitative panel data. By contrast, this study draws on a unique qualitative dataset of 72 extreme poor households across Bangladesh, examining how inter- and intragenerational bargains generate extreme poverty. It is argued that, while poverty is transferred inter-generationally, it is not transferred equally. Rather, transferred disadvantages are shaped by persistent forms of deprivation, discrimination and a household-level political economy that is highly gendered. The inter-generational transfer of poverty should be seen as a dynamic and negotiated process that is crucially shaped by intra-generational bargains.
\end{abstract}

Keywords Generational bargain · Disadvantages · Extreme poverty · Gender · Bangladesh

Owasim Akram

Owasim.Akram@oru.se; akramir@gmail.com

Mathilde Maitrot

mm880@bath.ac.uk

Thomas Denk

Thomas.Denk@oru.se

1 Örebro University, F2212, Fakultetsgatan 1, 70281 Örebro, Sweden

2 Social and Policy Sciences, University of Bath, Bath, UK

3 Department of Political Science, Örebro University, Örebro, Sweden 


\section{Résumé}

Pourquoi les personnes en situation de pauvreté restent-elles pauvres? Et surtout, pourquoi leurs enfants sont-ils susceptibles d'être en situation de pauvreté et de le rester plus tard dans la vie? Voilà une question commune dans les domaines du développement, de la politique sociale et de l'économie. Le Bangladesh a connu des succès notables dans la réduction de la pauvreté et pourtant, la lutte contre le transfert de la précarité et du désavantage au sein des générations, et entre elles, pose toujours un défi majeur aux décideurs. À ce jour, la littérature sur la pauvreté intergénérationnelle reste dominée par d'importantes données de panel quantitatives. En revanche, cette étude s'appuie sur un ensemble de données qualitatives uniques de 72 ménages extrêmement pauvres à travers le Bangladesh, et examine comment les négociations inter et intra-générationnelles génèrent l'extrême pauvreté. Nous soutenons que, si la pauvreté est transférée d'une génération à l'autre, elle ne l'est pas de façon égale. $\mathrm{Au}$ contraire, le transfert du désavantage est façonné par des formes persistantes de précarité, de discrimination et par une économie politique au niveau des ménages qui est fortement sexospécifique. Le transfert intergénérationnel de la pauvreté doit être considéré comme un processus dynamique et négocié qui est fondamentalement façonné par les négociations intra-générationnelles.

\section{Introduction}

Pockets of entrenched poverty persist in societies across the world, even those with strong macro-economic growth. This kind of poverty is commonly referred to as 'chronic', 'ultra' or 'extreme'. A distinct feature of such poverty, shared across these definitions, is that it is often inter-generationally transmitted. Although categorical distinctions should not be overstated, given the dynamic nature of poverty and the churning of the poor's fortunes, experiences of extreme poverty share characteristics of social isolation, exclusion from support networks and a prominence of femaleheaded or managed households. There is a concerted effort to improve the quality of rates of poverty in most of the Global South, yet the processes through which extreme poverty is transmitted inter- and intra-generationally remain under-analysed. In Bangladesh, for example, despite remarkable achievements in the Millennium Development Goals (MDGs) and sustained economic growth, around 20 million people (12.9\%) are still living below the poverty line (BBS 2017; Wood et al. 2018). Furthermore, in terms of absolute count, the number of extreme poor will likely increase in the coming decades, despite the fact that the percentage-wise share may go down, as the rate of progress has stagnated or slowed (Roser and OrtizOspina 2013). Such statistics raise the question: why do some people stay poor? Understanding why the children of poor people are also likely to be poor or end up as poor during their late life is then a crucial concern for policy-makers. 
The present work examines these questions drawing on a qualitative longitudinal dataset compiled by the EEP/shiree ${ }^{1}$ programme. The data were collected annually from 72 extreme poor households from 2008 to 2016. The core analysis focusses on how inherited material deprivations (namely assets and inheritance, health, education and skills) often translate into relational disadvantages that play a key role in 'trapping' the extreme poor within exploitative relationships over long periods of time. It is argued that inter-generational transfer of poverty is shaped by the intragenerational bargaining within the household, which has a significant and gendered impact on the reproduction of poverty between the generations. This argument has strong implications for development programming and poverty reduction strategies, promoting a view of the extreme poor as relationally as well as materially poor.

The remainder of this manuscript is organised as follows: The first section reviews existing literature on extreme poverty and inter-generational poverty, not in an attempt to be comprehensive but to deploy a useful analytical framework that will organise later empirical discussions on the inter- and intra-generational transfer of extreme poverty in the studied population. The second section introduces the methodology and data on which the analysis is based. The third section analyses how inter- and intra-generational extreme poverty occurs and persists, and attempts to draw lessons for development programming.

\section{Framing Generational Transfers of Disadvantages}

\section{Poverty and Extreme Poverty in Development Thinking}

Poverty reduction is a global priority for development organisations, embodied in the MDGs and, more recently, in the Sustainable Development Goals (SDGs). Even in high-performing economies, a significant minority of the population remains extremely deprived or poor (Green and Hulme 2005). The presence and persistence of 'traps' keeping people in poverty across the world has led to conceptualisations of chronic/extreme forms of poverty as distinct (Shepherd et al. 2011). Development programmes led by governments and donor agencies have designed an array of approaches to alleviate poverty, often targeting those deemed the most 'extreme'. Such approaches persistently rely on a finance-centric understanding of poverty, focussing on incomes, expenditure and consumption, variables deemed more

\footnotetext{
${ }^{1} \mathrm{EEP} / \mathrm{shiree}$ was a poverty reduction programme implemented in Bangladesh in partnership with the UK Department for International Development (DFID), the Swiss Agency for Development and Cooperation (SDC) and the Government of Bangladesh (GoB). The programme was widely known as 'Shiree' - the Bangla word for 'steps' - the name is an acronym for 'Stimulating Household Improvements Resulting in Economic Empowerment' which reflected the programme's core approach: to provide households with the assets and support needed to take enduring steps out of extreme poverty. See www. shiree.org for further details.

2 The definition of extreme poverty differs and, in the context of a development programme and the SDGs, commonly refers to people with incomes below a certain threshold that is adjusted to the particular national context and is designed to reflect the capacity to achieve a minimum set of basic needs.
} 
measurable and trackable in terms of long-term and spatial trends and amenable to national and international comparisons. A wide range of critiques have however been wagered against this vision of poverty, including accusations that income-based measurements are flawed, misleading, superfluous and easily manipulated (Jayaraj and Subramanian 2017). Even assuming economic wellbeing as an important indicator to distinguish the poor and extreme poor from those who are not, there is still a debate whether economic wellbeing can simply be measured using incomes, expenditures or consumptions figures (Posel and Rogan 2016). Furthermore, as Davis and Baulch (2009) have argued, by focussing on ever increasingly sophisticated poverty estimations techniques and on concerns about the reliability and interpretability of poverty metrics, researchers neglect the lived experiences of poverty and fail to differentiate the outcomes and manifestation of poverty from its causes.

Alongside dominant material approaches to conceptualising poverty are the alternative understandings, which incorporate the immaterial and relational dynamics of poverty and its reproduction (Wood 2003; Mosse 2010). Moving away from materialistic understandings of poverty, Sen's ideas of freedom and capabilities for example places the question of absence of entitlements at the centre of poverty analysis (Sen 1981, 1999). He argues that poverty is composed of social relations enabled by sets of entitlements (including nutrition, health, education and self-respect), which are contingent on specific social and cultural configurations (Chiappero-Martinetti and Moroni 2007). Similarly, analyses of adverse incorporation and social exclusion explicitly link individual situations of poverty to the broader social, political and political-economy context and thereby can generate a thick understanding of how poverty is reproduced at the household level (Hickey and du Toit 2013). A common denominator to such approaches is the measuring of deficits (be it related to assets, knowledge or capacities) and deprivations within broader relational and temporal frameworks. Extreme poverty within this perspective must thus be understood within a political-economy context that inhibits, exploits and differently enables the capacities of the extreme poor. Beyond a definition of extreme poverty as a level of consumption below an arbitrary threshold, more qualitative understandings see it as deeply entrenched within and inherited across generations. ${ }^{3}$

Examining the reproduction of poverty necessitates analysing the dynamic interaction between systemic and idiosyncratic risks. The distinction between systemic and idiosyncratic dates back to Kanbur (2001) and provides a helpful analytical lens through which poverty can be explored. Systemic routes to poverty are typically characterised by hazardous and precarious engagements with the labour and petty commodity markets. Although it can be argued that the 'moderate poor' endure more systemic barriers whilst being vulnerable to idiosyncratic shocks, "the extreme poor may experience, idiosyncratic poverty and poverty relating to horizontal inequalities, but are highly vulnerable to systemic, relational poverty whenever their livelihood depend directly upon petty commodity or labour markets" (Wood 2018,

\footnotetext{
3 Many extreme poverty programmes (including the 'EEP/shiree' programme) incorporate some elements of this into their operational definition of extreme poverty; For example beneficiaries targeted may be a widow or female-headed household in addition to having income below a certain threshold.
} 
p. 8). In other words, as the extreme poor work for the betterment of their condition, they move from a condition of social exclusion to adverse incorporation, facing more prejudice and discrimination than their moderate poor counterparts. Yet, much of these idiosyncratic and systemic forces that result in the exclusion or exploitation of an extreme poor household should be understood in the light of previous experiences and processes of exploitation and exclusion that are specific to this household, two compatible phenomena.

\section{Understanding Generational Transfers of Disadvantages}

For the vast majority of the extreme poor, social exclusion and deprivation are not a sudden occurrence. They work hard relentlessly to prevent and cope with vulnerabilities and risks brought on them by systemic forces that hamper their efforts (Hulme and Lawson 2010). The transfer of deprivations and disadvantages taking place within and between generations poses some challenging societal questions about inequalities (Musick and Mare 2004). Although the bulk of the research on intergenerational poverty is often dominated by large quantitative panel data, through the 2000s, a resurgence of scholarly interest in exploring how poverty is reproduced inter-generationally has taken place. ${ }^{4}$ This is often framed as a 'transfer' between generations, which often occurs within the boundaries of the household and relates to the accumulated set of exposure to opportunities, constraints or disadvantages during the parents' life cycle and inherited by the child. Although part of this transfer process can be considered conscious and intentional, a large part of it is less palpable and deliberate.

As stated above, a salient feature of inter-generational poverty is that it describes a time-based process (Bird et al. 2010) which goes beyond the life of an extreme poor household to its offspring. Therefore, inter-generational poverty not only represents an outcome, children's poverty, but a cause, the older persons' poverty, that of previous and future generations. This also indicates that a person's ability to move upwards over his/her life is determined by diverse household-based, community or wider external factors that are out of their control (Cooper and Bird 2012). Both positive and negative resources can be inherited from previous generations, an inheritance package that combines assets, reputation, values and aspirations, labour arrangements, health, religion and traditions (Harper et al. 2003; Musick and Mare 2006). Poverty passes from one generation to another due to a lack of inputs, resources and capitals, along with poor health, forced child labour, inadequate access to education, low self-esteem and inadequate social status (Moore 2001).

Critically, the transmission of resources from parents to their children is not a static process but often bargained between generations and across generations, within families and relations. McGregor et al. (2000, p. 447) defined inter-generational bargains as a pattern of relationships through which generations transfer resources which come with uncodified rights and obligations. Inter- and intra-generational

\footnotetext{
${ }^{4}$ From, for example, the Chronic Poverty Research Center (CPRC), the Oversees Development Institute, the Institute of Development Studies in Sussex and the Centre for Development Studies at Bath
} 
bargains can be associated with the transmission of disadvantages, liabilities and inequalities between generations (Anderson 2013), while also representing a means by which one generation makes sacrifices and strategic decisions for their children. Collard (2001) argues that a transfer of resources (both material and non-material) from one generation to the next is very common in their life cycles, and the process is very complex and often reciprocal; For instance a child is dependent on his/ her parents who hold the bargaining power and authority until a power shift occurs when children become earning members of the family and their ageing parents start relying on them (Kalenkoski 2008). Thus, the inter-generational bargain influences each party in different ways.

Education, for example, is often thought of as an enabling factor to long-term security and higher wages for poor households and their offspring (Bird et al. 2010). The motivation for sending children to school depends on the perceived benefits of formal education, which has important implications in transferring prospects or constraints for children to overcome their poverty. Children of uneducated parents find it difficult to continue their education (Behrman et al. 2017). It has also been argued that it is the education rather than economic status of parents which is more important in determining whether the children of the household go to school (Horii and Sasaki 2012). In extreme poor households, choosing to send children to school is influenced by a calculus of the perceived losses (loss of labour and schooling related costs) against the future possible benefits of enhanced earnings.

The bargaining process is often highly gendered. A woman's position in her family and in society (in terms of the gendered differences in exercising rights, nature of obligations and capacity to access opportunities) plays a key role in determining the next generation's fortune; For example research conducted in Bangladesh found that many extreme poor female-headed households place their children in orphanages to cope with food insecurity, a group of children one author termed 'food orphans' (Akram 2018). Another example of this concerns the importance of women's good health during pregnancy. Extreme poor pregnant women who have had and continue to have a poor diet during pregnancy and receive inadequate antenatal care are more likely to give birth to children who experience congenital malformations, sudden infant death syndrome and become under- or malnourished (Smith and Ashiabi 2007). For breastfed babies, poor nutrition in early life can have lifelong consequences, including stunting, limited body development or delayed cognition, which in turn can lead to low working and earning capacity (Martorell and Zongrone 2012; Caulfield et al. 2006). In all those cases, it might be worth reflecting on what the future of those children could look like. The answer in many cases would be 'poverty' or even 'extreme poverty'. Inter-generational influences are thus so strong that they produce an 'inter-generational cycle of growth failure', also referred to as consistent growth failure by Martorell and Zongrone (2012).

The concept of a 'generational bargain' is used herein to refer to a person's inheritance of assets, skills, opportunities and vulnerabilities that typically shape their identity, defined herein as the nature and terms on which it is possible for them to interact with the outside world and their capacity to improve their condition within it during their life course. This reflects the bargains and decisions made by households and between generations but is also conditioned by the political economy of 
the household. In examining inter-generational poverty through this lens, the intention is thus to contribute to the growing interest among policy-makers, academics and development researchers in understanding how inheritance influences one's life chances and exploring how this transfer influences people's capacity to escape from or remain in extreme poverty across generations. Understanding this may prove crucial to design effective extreme-poverty-alleviation interventions, and yet academic scholarship exploring the patterns and processes through which household dynamics, reciprocal exchanges and bargains within and between generations impact experiences of extreme poverty remains scarce.

\section{Methodology}

\section{Data}

Inter-generational poverty has mostly been understood through quantitative panel datasets, which arguably often neglects the wider context and processes through which such transmission occurs and the dynamism of this through people's lives (Heissler 2012). ${ }^{5}$ By contrast, the present analysis draws on the baseline of a secondary qualitative longitudinal dataset ${ }^{6}$ developed as part of the monitoring and evaluation component of an extreme poverty reduction programme. Analysing this dataset enabled the authors to examine the multiple processes through which inter- and intra-generational bargains occur within extreme poor households.

The qualitative dataset used tracks the livelihood trajectories of 72 extreme poor $^{7}$ households over a 5-year period, from 2010 to 2015 . The sampling of the 72 households was done purposively to cover the wide range of interventions taking place as part of the EEP/shiree programme (implemented by 17 NGOs) and therefore attempts at capturing a wide range of experiences of extreme poverty. ${ }^{8}$

\footnotetext{
${ }^{5}$ For example almost all of the inequality-related studies in Bangladesh draw estimates from the household income and expenditure survey (HIES) or panel data available; however, the national HIES is often accused of not providing satisfactory levels of estimates of the changes in peoples' lives over time (Khan 2005).

${ }^{6}$ This is an open access dataset free to be used acknowledging the source. The first and the second authors played a significant role in collecting and managing the data, and the principal investigator for the project has given consent to use the dataset for this research.

7 In line with the national Household Income and Expenditure Survey (HIES), EEP/shiree considered "the extreme poor as those households for whom total expenditure falls at or below the lower poverty line. What this means is that the extreme poor are unable to meet even their basic dietary requirements. Most beneficiary households fell within the poorest $5 \%$ of Bangladeshi population. Often, these households suffer from multiple deprivations and have limited or no assets (such as land, livestock or shelter), secure employment opportunities, social or political capital, ability to withstand or recover from shocks, access to health, education and other services." Source: www.shiree.org.

${ }^{8}$ The project established a comprehensive monitoring system named Change Monitoring System (CMS). The dataset used for this work was also known as CMS5. However, this was managed in an academic manner independently of the typical monitoring system followed in development programmes. The details of the organisation of the EEP/shiree intervention, its monitoring system and sampling can be found on the EEP/shiree website.
} 
Geographically, the present study covers multiple regions, with 25 households living in coastal areas, 25 in Northern Bangladesh-including the monga-prone areas (characterised by seasonal food insecurity), char and haor areas and Santal (ethnic minority of the north) community of the Barind region-12 in the Chittagong Hill Tracts (CHTs) and 10 in urban slum settings.

The number of times each household was visited varied (32 households were visited four times, 39 households three times and 1 household twice ${ }^{9}$ ). This variation can be explained by the two-stage recruitment process of the extreme poverty intervention. The second cohort of 40 respondents were recruited 2 years after the first cohort of 32 respondents (2012 and 2010, respectively). The 72 households were repeatedly interviewed by research officers (ROs), mentored by a team of senior researchers from the University of Bath, UK. Typically, one RO was assigned six beneficiary households. Thus, repeated visits over several years enabled ROs to develop a strong personal rapport with each of them and provided ROs with detailed contextual knowledge about the households. This way, information was collected in a semi-ethnographic manner.

As part of the programme, two different tools were used to track the households: baseline life histories and 'reflection on interventions'. For the purpose of this analysis, only data derived from the life histories were considered, as the aim was to keep the analysis clear of the EEP/shiree intervention's effects on the beneficiaries' lives. The life histories contain two elements: (1) a detailed narrative of crucial events that had affected the lives of the extreme poor beneficiary, in terms of wellbeing level and poverty status, since their birth and prior to the intervention; and (2) a map illustrating the self-reported variations in wellbeing status and events on a timeline. Six categories were used in the life histories to determine wellbeing statuses: destitute, working extreme poor, moderate poor, lower-earning non-poor, middle elite and wealthy elite (Table 1), a framework adapted from Davis $(2005,2006,2007) .{ }^{10}$

The life histories enabled the examination of detailed information relating to a wide range of topics from health to diet and migration to marriage, politics, environmental changes and deeper personal reflections on empowerment and the 'self' (Goto et al. 2011). From fieldwork preparation to transcription, each life history required an average of 15 working days, given that the data collection for each of them required between three and five consecutive visits to the household (and in some cases some phone calls to fill in some remaining gaps). The process engaged the participants as co-producers of knowledge. Once each script was finalised, the participants were consulted to validate the information gathered. The life history dataset was then manually coded by the authors and analysed for the purpose of this particular analysis to shed some light on inter- and intra-generational bargains.

\footnotetext{
9 This particular household was visited only twice because members migrated and could not be traced by researchers the following years.

10 A similar framework was also used by the Chronic Poverty Research Centre (CPRC, UK) and further adapted for this research.
} 


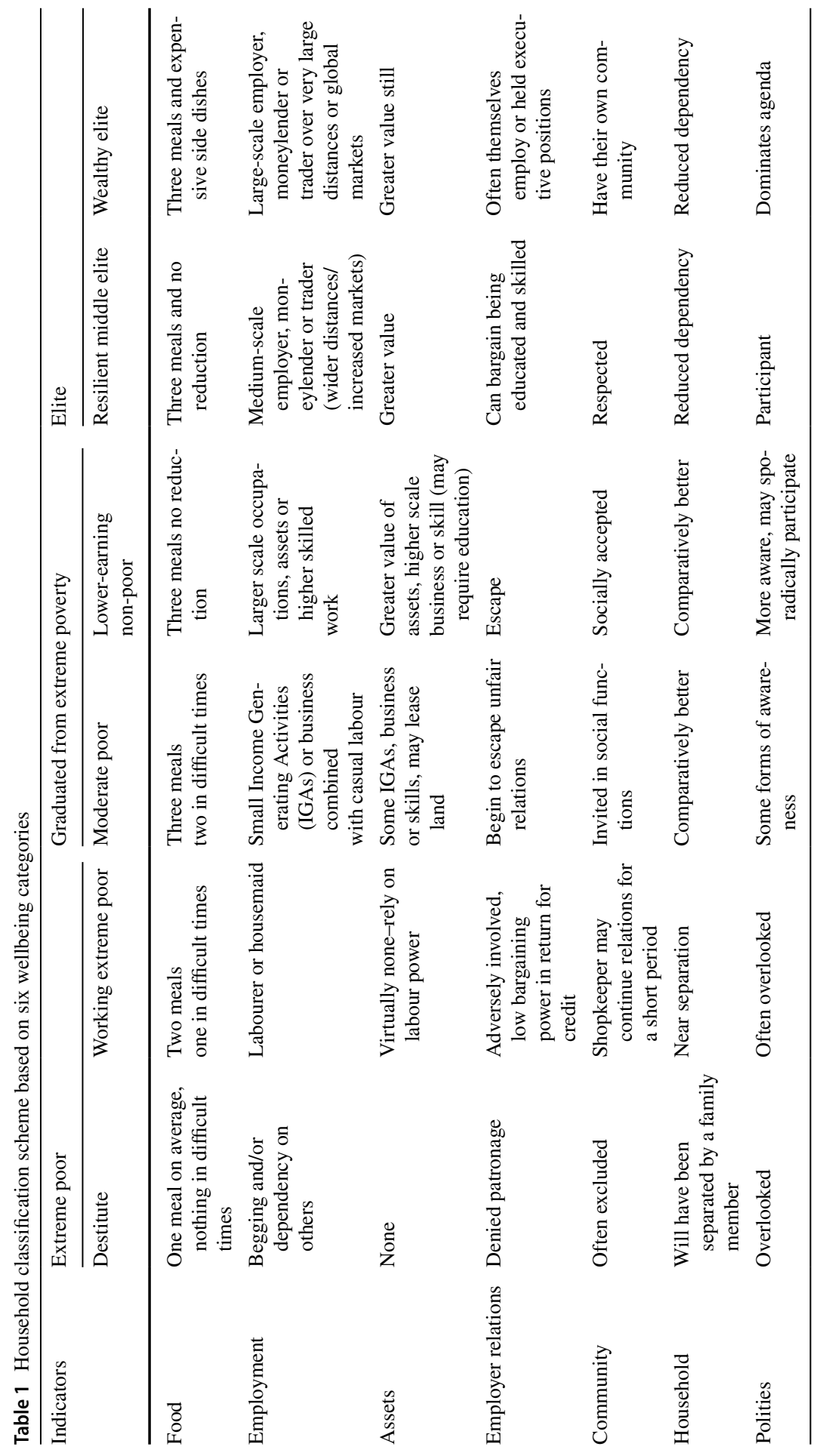




\section{Characteristics of the Sample}

Although the sampled households are all categorised as extreme poor, they are distinguished by a wide range of demographic characteristics.

Most of them ( $82 \%$ of which most are women) report having experienced poverty in their childhood (belonging either to the level of destitute, working extreme poor or moderate poor). Only 13 respondents categorised themselves as having belonged to the level of lower-earning non-poor. None of the respondents reported having experienced middle elite or wealthy elite wellbeing status during their childhood. Demographic characteristics such as disability, old age, female-headedness and female-managed households distinguish the 72 households. Of the total respondents, 52 were women of female-headed and female-managed households and 20 were men from male-headed households, with an average age of 39 years overall. The large majority (76\%) of them had no formal education, 11 of them had had primary level schooling and only 6 of them had high-school-level schooling experience.

\section{From Deprivation to Discrimination and Disadvantage: Inter- and Intra-generational Dimensions of Extreme Poverty}

The life histories reveal that, as diverse as the personal experiences of extreme poverty can be, the extreme poor share a common sense of disruption in accumulating skills and assets (and struggle in protecting them), erosion of supportive social connections and networks and the feeling that their aspirations and dignity have been crippled. Respondents typically construct and make sense of their life stories by explaining how they became excluded from rights and unjustly lost their entitlements, how they became unable to sustain a living as working-age adults and fell into extreme poverty as they were unable to rely on others.

There are multiple dimensions and issues that emerged from the analysis of the longitudinal qualitative data. This section is organised to reflect how respondents themselves made sense of their life experiences and of how and why their bargaining power weakened, leading them to a point of absolute deprivation. To reflect this notion of 'time' and personal experience, fundamental to exploring the bargaining process, the data analysis is organised as follows: the first section looks at material deprivations often stemming from systemic failures as a starting point in the process, then how these deprivations became the basis for discrimination is examined and finally how lingering discrimination or exclusion transformed into idiosyncratic risks and inherited disadvantages is studied. In this section, how this transfer takes place is explored in the following dimensions emerged frequently from the data: assets, health and nutrition, education and skills, relationships and inter- and intra-generational bargains.

\section{Owning and Inheriting Assets}

The successful accumulation and transfer of assets through inheritance represents a significant aspiration in the life of extreme poor households, especially because 
limited assets were (or to be) owned by multiple members; For instance an extreme poor family who owns a small piece of three decimal arable or homestead land has three children who are the future possible inheritors. The data show a strong gender differential treatment takes place during these processes and bargains, notably in the transfers of productive assets.

Contrary to the impression that male inheritance is clearly defined, in rural areas, when members of households become incapacitated or die, productive assets (e.g. land, livestock, or pieces of equipment) are often shared on an ad-hoc and unpredictable basis across male siblings. This is a crucial time when female and younger or 'weaker' siblings (weaker in terms of education, potential earning capacity and general bargaining power) become deprived in comparison with their elder or stronger male counterparts who mainly influence or initiate decisions in ways that favour them. Although religion plays a structuring role in conceiving this transfer, in practice culture is found to supersede specific religious principles. Customary practices are generally shared across households living in the same locality regardless of their religious beliefs (although with some exceptions in the $\mathrm{CHT}$ ).

In extreme poor households, transfers from parents to their daughters occur mostly at the time of marriage under the form of gifts or dowry. Women are often excluded from asset ownership and inheritance because dowry is considered to be their only entitlement. In most cases, women reported having been deprived of both their inheritance and their control over marriage dowry. This occurs through diverse means; For example Halima (46) was required to marry a disabled man so her brother could avoid giving her dowry. She neither inherited land from her family nor received a share of the 200 betel nut and coconut trees owned by her father. Furthermore, the data strongly indicates that even the few women who inherit or accumulate assets by their own means struggle to fully control them and often are excluded from being consulted about their use, sale or transfer; For example, when Marium's (32) husband died in a road accident, she and her two children were not allowed to control the BDT 30,000 (approximately USD 350) compensation received from the transport owners association. Her father-in-law took control over the money arguing that her husband had overdue loans, which Marium was not aware of. Rafeza (40) was married when she was only 15 . Her brothers decided to marry her off to a much older man who was on low income and who was already married. This was done so that they did not have to pay the dowry to the groom or sell the land that they would have inherited later.

In some cases, however, for working men, inheriting assets can in fact limit mobility. Although migrating entails high exposure to hazards and risks for the working extreme poor, especially during the first few months, ${ }^{11}$ many respondents reduced their vulnerability and improved their wellbeing by using it as a strategy to access employment or cash-based wages, while leaving their families in the village. In such contexts, the inheritance of a small piece of homestead land restricts one's

11 This is often due to their lack of reliable relationships and information in a new environment characterised by volatility and uncertainty. 
ability to migrate, as it brings expectations to remain in a natal village to take care of the inherited land, although there could be better economic opportunities elsewhere.

A large number of respondents reported that their comparative lack of assets, skills and knowledge restricts their access to cash-generating activities on the labour market. The terms of their engagement with it are often limited to in-kind payments and reliance on arrangements such as live-in and bonded labour, advance sale of labour, often characterised by precarious work, dominating patronage structures and low wages. These types of access to labour options certainly benefit the extreme poor in giving them means of subsistence, but they also usually bring complex longterm relationships and liabilities. Because of these arrangements and obligations, when experiencing a shock or hazard, the extreme poor face periods of severe hardship induced by an immediate loss of income often combined with negative coping strategies which include distress sale of assets, use of child for waged labour or caring duties, borrowing money (at high-interest rates) and reduction of food consumption and quality. When prolonged, these have damaging snowballing long-term effects. The future is discounted against, a process which Wood (2003) termed 'the Faustian bargain' (Wood 2003); For example sons are pulled out of school because employing their time for education is an immediate expense that, compared with their possible earnings, is not affordable to parents. Because young girls have fewer opportunities to engage in paid work, they are often pulled out of school to enable their mothers to work whilst care and house-chores duties are performed by their daughters.

The gradual depletion of tangible and intangible assets further narrows the households' opportunities for choice and weakens their social status. Protecting accumulated and earned gains becomes a struggle, and the prospects of improving the household's immediate wellbeing an unattainable aspiration. Parents become concerned with preserving their children from inheriting the disadvantages they have themselves inherited; For example the data shows that young girls (between 12 and 18 years) are pulled out of school to get married so that the dowry remains relatively low, particularly when the young girl is married off to a significantly older man or a man with some form of disability or sickness. The strategic use of children as instruments in households' livelihood often reflects severe forms of household destitution and gender discrimination, in this instance perhaps placing the value of the women and girls' future wellbeing below the value of their immediate wellbeing. Femaleheaded and female-managed households included in the dataset linked being overexposed to such arrangements with gender-based discriminations on the labour market (their involvement in precarious hazardous low-paid forms of employment) and their related limited access to and control over assets, usually explained by their limited contribution to the household's finances. Thus, in female-dependent households, children were found to face more disadvantages compared with the children in a male-dependent household.

Note that issues of asset depletion, gender discrimination and labour disadvantages were a significant transfer observed across all geographical sites. However, extreme poor households living in the CHTs experienced a comparatively lower level of intra-household tensions over inheritance of production assets. This might be because land is the most crucial productive asset in extreme poor families, and 
in CHTs, land rights are communal rather than individual (Roy 2000; Chowdhury 2008), which is regulated by the circle chief, headmen and village headmen.

\section{Poor Health and Nutrition}

Health is a major driver of extreme poverty, playing a significant role in determining the fortunes of the households studied. There is strong evidence that health-related disadvantages can be transmitted from one generation to the next. Poor health not only erodes the minimum assets of the households but also the future prospects and ability to work and earn, generating the type of negative coping explained above.

Problems such as ulcer, acidity, chest pain and headache were common, for which they lost workdays, and prolonged periods of hunger or malnutrition coupled with intense physical labour resulted in long-term health weakness for the extreme poor. Aside from being a negative outcome of a coping strategy, poor health often presents a basis for extreme poor households to be discriminated against and, the analysis suggests, becomes an inherited disadvantage. The data show that the presence of infectious and communicable diseases (e.g. asthma or tuberculosis) passed from parents to children among extreme poor households resulted in prolonged periods of sickness, loss of workdays and, in many cases, permanent disability or death of family members. Highly communicable diseases such as tuberculosis are heavily stigmatised, which results in social isolation or exclusion of households.

Extreme poor households spend a proportionately large share of their income towards accessing low-standard health services. A significant number of extreme poor households reported having developed long-term illnesses as a consequence of ignoring a particular health concern at the early stages. Postponing treatment or reluctance to create new expenses (often in case of women members of the family) causes minor and curable illnesses to transform into important life-long diseases, disability and prolonged periods of sickness or death. The fact that extreme poor households lack information about these diseases or have limited access to (or trust in) effective means of prevention and treatment can exacerbate the impact of the disease, enabling its spread to other family members or the worsening of their condition; For example Mong (34), who lived in the CHTs, experienced multiple health shocks that reduced his ability to work. He visited a number of healers, ranging from herbalist and faith healers to medical doctors. Mong explained that he had no choice but to sell his labour in advance as well as borrowing from moneylenders at highinterest rates to meet the costs of treatment. Although health-related concerns are common across all the life histories, respondents located in the CHTs tend to suffer most from it compared with households living in the plain land. This can be explained by the remoteness, inaccessibility and discriminatory practices that characterise public health services, often operated by Bengalis. Prolonged care-seeking processes often aggravate the health of the patients' condition.

There is evidence from the life histories that diseases and nutritional deficiencies of parents (particularly mothers) contribute to the deaths of extreme poor children. There are frequent examples of stillbirth, child death and also weak-cognitive and nutritional status of extreme poor children born with lifelong disadvantages, for 
example disabilities because of the lack or absence of access to antenatal care and/or malnutrition of mothers. Poor housing and unhygienic living conditions combined with poor nutrition negatively impact on the development (cognitive and physical) of children. Lack of cognitive skills (self-reported) was apparent among household members and restricted their work capacity, feeling of self-worth and ability to maintain and build supportive inter-personal relationships and networks. Disabled and older household members are the most vulnerable sub-groups within the extreme poor population, living with poor access to amenities, care and livelihood options, and a feeling of exclusion.

\section{Interrupted Education}

The data collected only allow to observe the impact of education on livelihoods in a limited way (given that the life histories have been tracking livelihoods for 5 years). Nonetheless, analysing parental decision-making processes in relation to education, according to their own background and experience, provides a lens through which to see the perceived beneficial outcomes and costs of schooling in the inter-generational bargain.

For extreme poor families, formal education often does not provide enough shortterm incentives when compared with other income-earning and non-income-earning activities. In fact, this often represents significant opportunity costs, as children's engagement in remunerated work and children's role in unpaid care work is considered productive in the sense that it enables parents to work outside home. However, the data indicate that the financial capacity of extreme poor households is not then the sole reason for not enrolling children in school or for them dropping out of school. Parents' perception of education plays an important role in children's schooling, more so than their financial capacity to do so. These are often influenced by visible wellbeing and wealth outcomes of educated people in their immediate kinship group. Therefore, children in families where parents had received some form of formal education tend to enrol their children at school more so than children whose parents received no formal education; For example Bidhan (37) reports that he was never encouraged to go to school because his father believed that a barber's son needed no education. Rather, he was trained as an assistant at his father's barbershop from the time he was only 10 years old. This was a norm and was believed to be more beneficial for the family. Similarly, respondents portrayed teachers as discriminating against their children in school due to prejudice, which either demotivates children to attend school or interrupts their learning motivation.

Choices concerning formal education are often ridden with gendered considerations. In extreme poor households, girls' access to formal education is determined by a specific set of factors. Grandparents' or other older family members often discredit the need for young girls to be educated as, they believe, it will risk delaying their marriage. For many of the girls, being able to read holy books (e.g. Quran in Muslim families) is perceived to be sufficient education and deemed more valuable than formal schooling. The present analysis partly confirms Horii and Sasaki's (2012) findings that households rationally anticipate that the benefits from education 
for poor children and their families will be low because children will not be given access to well-paid jobs and remain discriminated against because of their socioeconomic background. However, this data also shows that children who have had some level of education tend to have access to supportive social networks that generate benefits for the entire household. These can help the household cope with shocks and hazards and also contribute to their overall security and status; For example a little education up to grade five gave Abida (27) strength to fight the adverse situations (avoid multiple abusive relations on her own) in her life, take the challenge to work outside the home, continue her children's schooling and still to look forward to live for her children with courage and confidence.

Respondents reported that the social safety nets and social protection schemes such as the conditional cash transfers and stipends for girls' education often incentivise parents to enrol children, particularly girls, at school; For instance Fahmida (48) enrolled her eldest daughter in a local government primary school in 1994, when she got to know that the family would get $10 \mathrm{~kg}$ rice or wheat per month as an incentive. Her son completed his primary education in 2004, but Fahmida could not continue her son's schooling because there was no such stipend/conditional support for high-school male students. Fahmida's eldest daughter, Morzina, had to leave school after she completed the eighth grade, as the allowance did not continue thereafter. This lack of formal education or interrupted education can generate a form of stigma in children's circles and form a basis for short-term discriminations as well as longer-term disadvantages on the labour market.

\section{Intra-household Relationships}

A crucial dynamic to the transfer of poverty between generations is, as already indicated above, relationships. The data collected strongly point to relationships and networks being a significant determinant of the fortunes of households, and one that is certainly inherited. The narration of the extreme poor respondents' lives appeared dominated by stories of new, broken, mended and weakened relationships formed through labour, kinship, patronage, politics and marriage. It appears that the extreme poor rely on multiple but fragile inter-personal arrangements that allow them to live and maintain their livelihoods. The data particularly reveals how intra-household relationships affect household's livelihoods and wellbeing. This section therefore focusses on exploring their significance for inter-generational transfers.

The life histories of the households studied demonstrate that multiple marriages, abandonment and divorce make women and children vulnerable to becoming extreme poor. They often play into pre-existing patrilineal and patriarchal power dynamics and reinforce asymmetries through allocating resources, responsibilities and obligations. Meeting the latter is found to generate high levels of stress and generally low self-confidence. After marriage, brides are often found to be the weakest and most vulnerable household member with the least bargaining power, until they become mothers (particularly if their child is male). Dowry is a means to secure a respectable position for the girl in her in-laws' house. The groom's family would normally demand more dowries for an older bride than a younger one. A bride's 
position (and confidence) in her in-law's house often depends on the dowry and marriage gifts the family received from her natal family. When negotiating for dowry, a lot of discussions usually take place between the two parties, yet the woman has little say in those negotiations. For many of the respondents, giving birth to a boy often brings much pride and prestige. Such pressures can lead to poorly spaced pregnancies and women's reduced agency over their bodies (food intake, pregnancies and household chores).

For example, after Jalmai's (30) father passed away, her brothers inherited 93 decimals of land to which Jalmai was entitled. Jalmai's brothers said that they were sympathetic towards her, but she had no rights over the land. She did not receive any share of her father's property and had no education either. She was married off at the age of 13. The marriage met the interests of her brothers and prospective in-laws. Her brothers sought a man who would demand little dowry. Jalmai's husband was sick and died a few years after their marriage. Since then, she has had no support and had to endure abuse from her in-laws, making her children suffer a childhood of extreme poverty and destitution.

The advantages of living in joint or extended families have long been recognised. One of the main advantages, as pointed out by Collard (2000), is that the extended family can provide insurance against some kinds of risks such as illness, shocks and bereavement. The data indicate a relationship between the gradual erosion of the joint family structure and extreme poverty; For example Sajida (50) describes falling into extreme poverty when she separated from her in-laws' house. She took a loan from a micro finance institution (MFI) to buy a van for her son and sold her land for her daughter's wedding and dowry. Later, her sons deserted her and she was left destitute.

In cases of re-marriage, men either leave their family with no income security at all or they maintain two or more marriages/households, which leads to reducing the scarce resources being allocated to the first marriage and its children. The data show that young men often re-marry for dowry purposes or when the economic and noneconomic value of their earlier marriage depletes. This often occurs when first wives do not give birth to a son, cannot become pregnant at all or have not met dowry expectations. This can create conflict within households and impact on the mental health and wellbeing of the first wife and of the children of the first union. When widowers re-marry, children from the first marriage often reported having experienced abusive relationships with their step-mothers.

Community-based relationships the extreme poor have are often limited but central to their search for security. Short-term support during a period of transitional hardship can have a profound impact on their wellbeing in the long run, the data show. Supportive and resourceful social networks can help them access salaried and skill-based work that, in turn, help overcome the inter-generational disadvantages of extreme poverty. Yet, disabled and old-aged individuals in poverty generally lack such social networks. 


\section{Inter- and Intra-generational Bargain}

Baulch and Davis (2008) argued that long-term declines in wellbeing were caused by intermittent crises of the households studied. They continued to argue that crises in households turned into a severe decline in wellbeing when two or three shocks occurred within a short span of time, including high health expenditures, dowry or wedding expenses. The present study's data shows how disability, illness and/or subsequent death of the main income earner of a family create a situation where another family member must take charge. In a large extreme poor family with many siblings, both inter- and intra-generational bargains can be intense and a great source of anxiety, stress and conflict. In this regard, relationships break or erode, re-form or revive through various trade-offs towards an individual search for security.

The data indicate that senior members and those perceived as powerful and knowledgeable (in terms of education, networks, skills and physical ability) often abuse younger and vulnerable members in this bargain and pursue their own interests. This contributes to keep the poor and the most vulnerable in poverty (or further into extreme poverty) and keep the better-off in a position of power (exercising their agency). The relationship amongst siblings often erodes as a consequence; For example the illness of Mintu's (60) father and subsequent death not only left him without any income security being very young but also allowed his elder brother to sell all the lands of the family and keep the money. At that time, being only 13 years old, Mintu was so young that he could not really understand what was happening and was left alone with his disabled mother, surviving through child labouring.

Another example of this is Jebunnesa (32), who was married very young and who, after the death of her husband, returned to her father's home to live with her son with the extended household. When her son was ill, her brothers pretended to not have any money, ignored his illness and refused to take care of him in any way. She said that, whenever they go to the market and purchase chocolates for their children, they do not bring any for her son, and their children would not share food with him, although they live in the same house. This makes her and her son feel neglected. Her brothers see no reason to give her anything. They are angry with her because their father sold his (their future) land to get her married (dowry). Although she never benefited from the dowry, she said, she has to bear the responsibility and be blamed for it, and so does her son.

In general, the findings refer to a trend similar to that identified by Dorward et al. (2009), the three broad types of strategies in the extreme poor households, namely 'hanging in', 'stepping up' and 'stepping out', where most of the extreme poor households, as found in the present work, remain 'hanging in' in the face of adverse socio-economic circumstances experiencing a high-level transfer of disadvantages. Erratic forms of crises were found to affect individuals' ability to cope and their offspring's future possibility to rely on supportive relationships to avoid and escape poverty. 


\section{Discussion and Conclusions}

This article examines the role of generational bargain and transfer in producing extreme poverty. Denied access to or depletion of material assets and capitals has been found as a recurrent determining factor shaping discrimination. The latter forms a gradual erosion and narrowing of social networks. The wearing-off of supportive relationships has multiple idiosyncratic and systemic pathways of impact on the poor's wellbeing and on the future liabilities and disadvantages carried by their children (including reputation, ill-health, label, exclusion and loan). The understanding of extreme poverty that is developed is then one in which this notion of the bargain is central, seen as a dynamic and relationship-laden phenomenon formed by a set of disadvantages that severely limit individual choice and prospects of securing arrangements or earned gains that could support social and economic mobility of the poor and their children. High degrees of inter- and intra-generational bargain not only impact on children's wellbeing but determine their access to future opportunities.

The data show a clear trend of poor households' family members adopting coping strategies that put the wellbeing of the children, women, older persons, disabled or ill-bodied members of the family at risk by imposing unfavourable arrangements on them (labour, care work, grabbing of land or assets and marriage). This form of unequal distribution, abuse and exploitation generates a type of poverty that is extreme in that it limits the employment opportunities of the children, creates a basis for discrimination and forms a long-lasting disadvantage that will affect their life fortunes. This points to the negligence of family for securing one's own livelihood at the cost of others'. Thus, a family can appear as a 'double-edge sword' which can both offer support and undermine the capacity to prospect of individuals (Hulme, 2004), a role that, despite being so important, has never been "adequately recognized in contemporary analysis (i.e. thinking small)" (ibid, p. 173).

A primary conclusion drawn from this analysis is that extreme poverty is not only material but also, to a large extent, relational, which greatly constitutes and exacerbates the overall experience of poverty and wellbeing. For Green and Hulme (2005, p. 9 of web copy), the extreme poor "are structurally constrained by the social relations which produce poverty effects" and thus further argued inter-generational transmission of poverty as an outcome of unequal social relations. This process of negligence leads to a special type of poverty that $\mathrm{Ci}$ (2013) termed as 'status poverty'. For $\mathrm{Ci}$, subsistence poverty is practically the most urgent but, in principle, the least important and comparatively easily resolvable. What makes subsistence poverty distinct is the type of social relations a household has access to, as elaborated above. While status poverty can make subsistence difficult or impossible, it also disallows the person from participating in a range of social affairs, which forms the basis of social capital and respect or dignity (Ci 2013).

Scholarship on inter-generational poverty focusses mostly on analysing the process of transfer from an older generation to the next (Harper et al. 2003; 
Cooper and Bird 2012; Krishna 2012; Bird 2013). Findings from this study shed light on other dimensions of transfers. In the context studied, much of the transfer process gets influenced by the siblings themselves; For example the decision about a girl's inheritance is greatly influenced by the presence of a male sibling or close male relatives. Even within male siblings only, inheritance is defined by how much one has over others in terms of age, education, responsibility and obligations within the family. Thus, the process of the transfer of extreme poverty is not only inter-generational but also intra-generational. In addition, it is crucial to remember that these transfers not only influence the poverty level of a person during his childhood, adulthood or late adulthood period but also predicts how a person will live their old-age period.

To cope with structural insecurities and risks, poor people accept relationships of dependency that reduce their agency and also their prospects of longterm improvement (Wood 2003; Mosse 2007, 2010). The findings suggest that this transfer of disadvantages from one generation to the next is highly gendered. Even in male-headed households, transfer of disadvantages across generations depends on the status and position of the mother. This helps explain why most of the respondents tracked in this study experienced living mostly in extreme poverty during their childhood.

While the analysis contributes to the existing knowledge base on extreme poverty and their routes, these findings, at the same time, have also broad implications for development practice and programmes in the field of poverty reduction. Escape from extreme poverty ought to be conceived as a strongly political rather than technical process in that it requires defying and challenging long-established power relations for households and individuals to accumulate 'gains' and 'protect' them. The data analysis shows how power is used to protect one's wellbeing on the one hand and generate deprivation, discrimination and longer-term disadvantages on the other. One critical implication is that the multi-faceted experience of extreme poverty and its reproduction suggest that interventions must be designed in a way that considers how project 'beneficiaries' are relationally embedded and how this significantly determines their ability and respond to a project. The emphasis in the present analysis is on intra-household relationships, raising complex questions about how (if at all) this can be addressed through development programmes.

Acknowledgements The authors are greatful to Prof. Joe Devine and Prof. Geof Wood of the University of Bath, UK along with Dr. Jan Jämte of the Örebro University, Sweden and Dr. Ilaria Pitti of the University of Siena, Italy for their overall guidance and mentoring support in the research. This study was accomplished within the context of the Swedish National Graduate School for Competitive Science on Ageing and Health (SWEAH) funded by the Swedish Research Council.

Funding This paper has been produced as part of a Ph.D. research project which has received funding from the European Union's Horizon 2020 research and innovation programme under the Marie Skłodowska-Curie Grant Agreement No. 754285. The qualitative panel dataset used in this research emerged from a project funded by UK aid from the UK Government (Grant Number: GB-1-107402). The views expressed do not necessarily reflect the EU's or UK Government's official policies. 
Open Access This article is licensed under a Creative Commons Attribution 4.0 International License, which permits use, sharing, adaptation, distribution and reproduction in any medium or format, as long as you give appropriate credit to the original author(s) and the source, provide a link to the Creative Commons licence, and indicate if changes were made. The images or other third party material in this article are included in the article's Creative Commons licence, unless indicated otherwise in a credit line to the material. If material is not included in the article's Creative Commons licence and your intended use is not permitted by statutory regulation or exceeds the permitted use, you will need to obtain permission directly from the copyright holder. To view a copy of this licence, visit http://creativecommons.org/licen ses/by/4.0/.

\section{References}

Akram, O. 2018. Food Insecurity of Extreme Poor Female-Headed Households in Coastal Bangladesh. In Aiding Resilience among the Extreme Poor in Bangladesh, ed. G. Wood, Z. Ali, M. Maitrot, and J. Devine, 281-320. Dhaka: The University Press Limited.

Anderson, M.W. 2013. Intergenerational Bargains: Negotiating Our Debts to the Past and Our Obligations to the Future. Futures 54: 43-52. https://doi.org/10.1016/j.futures.2013.10.002.

Baulch, B., and P. Davis. 2008. Poverty Dynamics and Life Trajectories in Rural Bangladesh. International Journal of Multiple Research Approaches 2 (2): 176-190. https://doi.org/10.5172/ mra.455.2.2.176.

BBS. 2017. Household Income and Expenditure Survey 2016; Bangladesh Bureau of Statistics, Dhaka, Bangladesh. http://bbs.portal.gov.bd/sites/default/files/files/bbs.portal.gov.bd/page/b343a 8b4_956b_45ca_872f_4cf9b2f1a6e0/HIES\%20Preliminary\%20Report\%202016.pdf. Accessed 31 Oct 2018

Bird, K. 2013. The Intergenerational Transmission of Poverty: An Overview. In Chronic Poverty. Rethinking International Development Series, ed. A. Shepherd and J. Brunt. London: Palgrave Macmillan. https://doi.org/10.1057/9781137316707_4.

Bird, K., K. Higgins, and A. McKay. 2010. Conflict, Education and the Intergenerational Transmission of Poverty in Northern Uganda. Journal of International Development 22: 1183-1196. https ://doi.org/10.1002/jid.1754.

Behrman, J., W. Schott, S. Mani, B. Crookston, K. Dearden, L. Duc, and A. Stein. 2017. Intergenerational Transmission of Poverty and Inequality: Parental Resources and Schooling Attainment and Children's Human Capital in Ethiopia, India, Peru, and Vietnam. Economic Development and Cultural Change 65 (4): 657-697.

Caulfield, L.E., S.A. Richard, J.A. Rivera, P. Musgrove, and R.E. Black. 2006. Stunting, Wasting, and Micronutrient Deficiency Disorders. In: Disease Control Priorities in Developing Countries, eds. D.T. Jamison, J.G. Breman, A.R. Measham et al, 2nd ed. Washington (DC): World Bank. Chapter 28.

Chiappero-Martinetti, E., and S. Moroni. 2007. An Analytical Framework for Conceptualizing Poverty and Re-examining the Capability Approach. Journal of Socio-Economics 36 (3): 360-375. https://doi.org/10.1016/j.socec.2006.12.002.

Chowdhury, K. 2008. Politics of Identities and Resources in Chittagong Hill Tracts, Bangladesh: Ethnonationalism and/or Indigenous Identity. Asian Journal of Social Science 36 (1): 57-78. https:// doi.org/10.1163/156853108X267567.

Ci, J. 2013. Agency and Other Stakes of Poverty*. Journal of Political Philosophy 21 (2): 125-150. https://doi.org/10.1111/j.1467-9760.2012.00417.x.

Collard, D. 2000. Generational Transfers and the Generational Bargain. Journal of International Development 12: 453-462. https://doi.org/10.1002/1099-1328(200005)12:43.0.CO;2-W.

Collard, D. 2001. The Generational Bargain. International Journal of Social Welfare 10: 54-65. https ://doi.org/10.1111/1468-2397.00152.

Cooper, E., and K. Bird. 2012. Inheritance: a Gendered and Intergenerational Dimension of Poverty. Development Policy Review 30: 527-541. https://doi.org/10.1111/j.1467-7679.2012.00587.x.

Davis, P. 2005. Power-Resources and Social Policy in Bangladesh: A Life-History Perspective. PhD Thesis, Department of Economic and International Development, Bath: University of Bath. 
Davis, P. 2006. Poverty in Time: Exploring Poverty Dynamics from Life History Interviews in Bangladesh, CPRC Working Paper 69.

Davis, P. 2007. Discussions Among the Poor: Exploring Poverty Dynamics with Focus Groups in Bangladesh, CPRC Working Paper 73.

Davis P., and B. Baulch. 2011. Parallel Realities: Exploring Poverty Dynamics Using Mixed Methods in Rural Bangladesh. Journal of Development Studies 47 (1): 118-142.

Dorward, A., S. Anderson, Y.N. Bernal, E.S. Vera, J. Rushton, J. Pattison, and R. Paz. 2009. Hanging in, Stepping up and Stepping out: Livelihood Aspirations and Strategies of the Poor. Development in Practice 19 (2): 240-247. https://doi.org/10.1080/09614520802689535.

Green, M., and D. Hulme. 2005. From Correlates and Characteristics to Causes: Thinking about Poverty from a Chronic Poverty Perspective. World Development 33 (6): 867-879. https://doi.org/10.1016/j. worlddev.2004.09.013.

Goto, R., L. Da Corta, N. Mascie-Taylor, and J. Devine. 2011. Quantitative \& Qualitative Analysis of the Changes in Extreme Poor Households (March 2010-March 2011). http://www.shiree.org/wp-conte nt/uploads/2012/02/Q2-Report-Analysis.pdf. Accessed 08 July 2019.

Harper, C., R. Marcus, and K. Moore. 2003. Enduring Poverty and the Conditions of Childhood: Lifecourse and Intergenerational Poverty Transmissions. World Development 31: 535-554. https://doi. org/10.1016/S0305-750X(03)00010-X.

Heissler, K. 2012. Children's Migration for Work in Bangladesh: the Policy Implications of Intra-household relations. Development in Practice 22: 498-509. https://doi.org/10.1080/09614524.2012.673555.

Hickey, S., and A. du Toit. 2013. Adverse Incorporation, Social Exclusion, and Chronic Poverty. In Chronic Poverty: Concepts, Causes and Policy, ed. A. Shepherd and J. Brunt, 134-159. Basingstoke: Palgrave Macmillan.

Horii, R., and M. Sasaki. 2012. Dual Poverty Trap: Intra- and Intergenerational Linkages in Frictional Labor Markets. Journal of Public Economic Theory 14: 131-160. https://doi.org/10.111 1/j.1467-9779.2011.01536.x.

Hulme, D. 2004. Thinking 'Small' and the Understanding of Poverty: Maymana and Mofizul's Story. Journal of Human Development 5 (2): 161-176. https://doi.org/10.1080/1464988042000225104.

Hulme, D., and D. Lawson. 2010. What Works for the Poorest? In What Works for the Poorest? Poverty Reduction Programmes for the World's Extreme Poor, 1st ed, ed. D. Lawson, D. Hulme, I. Matin, and K. Moore, 1-22. Rugby Warwickshire: Practical Action Publishing.

Jayaraj, D., and S. Subramanian. 2017. The Iniquity of Money-Metric Poverty in India. Basic Income Studies 12 (1): 36-42. https://doi.org/10.1515/bis-2016-0005.

Kalenkoski, C. 2008. Parent-Child Bargaining, Parental Transfers, and the Post-secondary Education Decision. Applied Economics 40: 413-436. https://doi.org/10.1080/00036840600690264.

Kanbur, R. (ed.). 2001. Qual-quant: Qualitative and Quantitative Poverty Appraisal-Complementarities, Tensions and the Way Forward. http://www.people.cornell.edu/pages/sk145/papers.htm.

Khan, A.R. 2005. Measuring Inequality and Poverty in Bangladesh: an Assessment of the Survey Data. Bangladesh Development Studies XXXI (3\&4): 1-34.

Krishna, A. 2012. Characteristics and Patterns of Intergenerational Poverty Traps and Escapes in Rural North India. Development Policy Review 30 (5): 617-640. https://doi.org/10.111 1/j.1467-7679.2012.00591.x.

Martorell, R., and A. Zongrone. 2012. Intergenerational Influences on Child Growth and Undernutrition: Intergenerational Influences. Paediatric and Perinatal Epidemiology 26: 302-314. https://doi.org/10 .1111/j.1365-3016.2012.01298.x.

McGregor, J.A., J.G. Copestake, and G.D. Wood. 2000. The Inter-generational Bargain: an Introduction. Journal of International Development 12: 447-451. https://doi.org/10.1002/1099-1328(20000 5)12:4\%3c447:AID-JID682\%3e3.0.CO;2-O.

Moore, K., 2001. Frameworks for Understanding the inter-generational transmission of poverty and wellbeing in developing countries. Chronic Poverty Research Centre Working Paper, (8).

Mosse, D. 2007. Power and the Durability of Poverty: A Critical Exploration of the Links between Culture, Marginality and Chronic Poverty. Chronic Poverty Research Centre Working Paper No. 107. https://doi.org/10.2139/ssrn.1615629.

Mosse, D. 2010. A Relational Approach to Durable Poverty, Inequality and Power. The Journal of Development Studies 46 (7): 1156-1178. https://doi.org/10.1080/00220388.2010.487095.

Musick, K., and R.D. Mare. 2004. Family Structure, Intergenerational Mobility, and the Reproduction of Poverty: Evidence for Increasing Polarization? Demography 41: 629. https://doi.org/10.1353/ dem.2004.0034. 
Musick, K., and R.D. Mare. 2006. Recent Trends in the Inheritance of Poverty and Family Structure. Social Science Research 35: 471-499. https://doi.org/10.1016/j.ssresearch.2004.11.006.

Posel, D., and M. Rogan. 2016. Measured as Poor versus Feeling Poor: Comparing Money-Metric and Subjective Poverty Rates in South Africa. Journal of Human Development and Capabilities 17 (1): 55-73. https://doi.org/10.1080/19452829.2014.985198.

Roser, M., and E. Ortiz-Ospina. 2013. Global Extreme Poverty. Our World in Data. https://ourworldin data.org/extreme-poverty. Accessed 07 Aug 2019

Roy, R. C. K. 2000. Land rights of the indigenous peoples of the Chittagong Hill Tracts, Bangladesh (No. 99). International Work Group Indigenous Affairs (IWGIA), Copenhagen. https://www.iwgia.org/ images/publications//0128_Chittagong_hill_tracts.pdf. Accessed 10 July 2019.

Sen, A. 1981. Poverty and Famines. An Essay on Entitlement and Deprivation. Oxford: Oxford, Oxford University Press.

Sen, A. 1999. Development as Freedom. Oxford: Oxford University Press.

Shepherd, A., et al. 2011. Tackling Chronic Poverty. The Policy Implications of Research on Chronic Poverty and Poverty Dynamics. Manchester: Chronic Poverty Research Centre.

Smith, D.E., and G.S. Ashiabi. 2007. Poverty and Child Outcomes: a Focus on Jamaican Youth. Adolescence 42: 837-858.

Wood, G. 2003. Staying Secure, Staying Poor: the "Faustian Bargain". World Development 31: 455-471. https://doi.org/10.1016/S0305-750X(02)00213-9.

Wood, G. 2018. Introduction. In Aiding Resilience among the Extreme Poor in Bangladesh, ed. G. Wood, Z. Ali, M. Maitrot, and J. Devine, 1-44. Dhaka: The University Press Limited.

Wood, G., Z. Ali, M. Maitrot, and J. Devine (eds.). 2018. Aiding Resilience among the Extreme Poor in Bangladesh. Dhaka: The University Press Limited.

World Bank. 1998. Bangladesh: From Counting the Poor to Making the Poor Count. Washington, DC: Poverty Reduction and Economic Management Network, South Asia Region, The World Bank.

Publisher's Note Springer Nature remains neutral with regard to jurisdictional claims in published maps and institutional affiliations. 